\title{
A Revolução das Novas Ideias
}

\author{
Áurea J. Chaves
}

$\mathbf{N}$ este momento, em que se finda mais um ano, também se finda a administração "Novas Ideias", que fez história na Sociedade Brasileira de Hemodinâmica e Cardiologia Intervencionista $(\mathrm{SBHCl})$. Testemunhamos em pouco mais de três anos uma verdadeira revolução, liderada por seu presidente Luiz Alberto Mattos, que diversificou, modernizou e expandiu áreas fundamentais da entidade, como educação médica continuada, certificação e qualificação profissionais, e mídias impressa e eletrônica.

A Revista Brasileira de Cardiologia Invasiva (RBCI), publicação oficial da $\mathrm{SBHCl}$, transformou-se, priorizando a publicação de artigos originais e editoriais de expoentes da especialidade, tornando-se consulta frequente de leitores que hoje são responsáveis pelos mais de $21 \mathrm{mil}$ acessos eletrônicos/mês ao portal www.rbci.com.br. Dentro desse universo, compartilhamos informações e recebemos contribuições de centros da América Latina e Península Ibérica, consolidando a RBCI como importante meio de divulgação científica nesses países, que não dispõem de revistas especializadas na área de intervenção cardiovascular percutânea publicadas em seu idioma nativo. O gerenciamento de submissão de artigos e revisão pelos pares é feito na sua totalidade por via eletrônica, o Conselho Editorial foi ampliado, recebendo membros dos principais centros intervencionistas do País, e uma equipe de assessores qualificados foi formada para produzir e revisar com rigor os textos a serem publicados.

Dentro desse período, trabalhamos intensamente para que a Revista, reconhecida e valorizada pelos leitores, recebesse o reconhecimento oficial de sua qualidade, por meio da indexação no Scientific Electronic Library Online (SciELO). Paralelamente, solicitamos, no final de 2009, a indexação no Medline, com a entrega, em mãos, do dossiê da RBCI ao editor executivo dessa instituição. A Revista foi representada por Rogério Sarmento-Leite, diretor de Comunicações da $\mathrm{SBHCl}$, e por esta editora, que, em reunião de pouco mais de uma hora, na Biblioteca Nacional de Medicina (Bethesda, Estados Unidos), expôs as características e esclareceu dúvidas a respeito de nossa publicação, demonstrando nossa determinação em incluir a RBCI nessa importante base de dados.

Independentemente dos resultados das indexações pleiteadas, prosseguimos com nossa meta de tentar obter sempre o melhor a cada edição, e, desde já, agradecemos o convite da Diretoria 2010-11 da SBHCI, nas pessoas de seu presidente, Maurício Rezende Barbosa, e de seu diretor de Comunicações, Alexandre Schaan de Quadros, para permanecer à frente da RBCI nos próximos dois anos.

Esta edição, dentro do padrão de excelência esperado pelos nossos leitores, traz artigos originais e editoriais que contemplam assuntos de muito interesse na especialidade, como a utilização da via radial em pacientes de maior complexidade clínica, os resultados da valvoplastia aórtica por balão em pacientes nos extremos da faixa etária, o impacto da resolução do segmento ST após intervenção coronária no infarto agudo do miocárdio, e a resistência aos antiplaquetários.

Andrade et al., da Santa Casa de Misericórdia de Marília (Marília, SP), trazem os resultados de quase mil procedimentos diagnósticos e terapêuticos realizados por via radial em mulheres, idosas ou não, com impressionante taxa de sucesso e muito baixas complicações. Spaulding et al., do Hospital Cochin (Paris, França), em editorial correspondente, fazem um paralelo interessante, lançando mão do roteiro de um popular filme hollywoodiano, das expectativas dos pacientes em relação a essa via de acesso, e apontam soluções para a correta incorporação dessa técnica em centros ainda sem experiência.

Carla Agatiello, com o apoio de pesquisadores do Hospital Italiano (Buenos Aires, Argentina) e do grupo de Alain Cribier (Rouen, França), relata resultados atuais da técnica da valvoplastia por balão em pacientes idosos com estenose aórtica grave e sua utilidade para alívio dos sintomas e seleção de pacientes para substituição percutânea da valva aórtica. Grube e Buellesfeld, do HELIOS Heart Center (Siegburg, Alemanha), em outra excelente contribuição, listam os inúmeros avanços técnicos recentes do procedimento e mencionam a interessante proposta da utilização adjunta da braquiterapia para reduzir a reestenose precoce desses pacientes.

Ainda dentro do tema da valvoplastia aórtica por balão, mas agora aplicada a neonatos e lactentes jovens, Costa et al., do Instituto Dante Pazzanese de Cardiologia (São Paulo, SP), apresentam os resultados imediatos do procedimento realizado por via carotídea, em termos de gradiente transvalvar, função ventricular 
e da capacidade de postergar a cirurgia nesses pacientes. Francisco Chamié, do Hospital dos Servidores do Estado MS/RJ (Rio de Janeiro, RJ), em verdadeira aula magistral, esgota o assunto, fazendo com que seu editorial se torne leitura obrigatória para aqueles que queiram ficar atualizados no tema.

Nova contribuição da América Latina, de Damonte et al., do Instituto Cardiovascular de Rosario (Rosário, Argentina), mostra os resultados da avaliação da resolução do segmento ST após angioplastia primária do Registro Multicêntrico de Infarto Agudo do Miocárdio da Argentina. A obtenção do fluxo coronário TIMI 3 em grande parte dos pacientes não foi acompanhada de porcentual semelhante de resolução completa do segmento ST, o que nos remete à reflexão de qual seria, então, o melhor marcador de sucesso desse procedimento. Editorial de Luiz Alberto Mattos, do Instituto Dante Pazzanese de Cardiologia (São Paulo, SP), aprofunda nossos conhecimentos nessa área e propõe, alicerçado em publicações recentes, a adoção de um novo marcador de sucesso da reperfusão miocárdica.
Por fim, Lopes et al., do Duke University Medical Center (Durham, Estados Unidos), em editorial especial, abordam um problema bastante discutido nos dias de hoje, que é a resistência aos antiplaquetários em pacientes submetidos a intervenção coronária percutânea, uma das causas de trombose dos stents. Expõem os limites dos testes de agregação plaquetária mais utilizados e lembram os novos inibidores do P2Y12, prasugrel e ticagrelor.

A partir desta edição, a RBCI será impressa em papel certificado pelo Forest Stewardship Council (FSC), organismo não-governamental estabelecido para promover o uso responsável de produtos florestais e, dessa maneira, reduzir o impacto ambiental. Teremos o direito de ostentar o selo FSC na capa, garantia de procedência da madeira, proveniente de florestas plantadas para esse fim, e, assim, trazer nossa pequena contribuição para a redução do aquecimento global.

Feliz 2010 a todos!

Áurea J. Chaves Editora 